\title{
Preventing waste oil from polluting river and coastal sea environments by a novel technology
}

\author{
M. Sumimoto ${ }^{1}$ \& T. Azuma ${ }^{2}$ \\ ${ }^{I}$ Sumimoto Scientific Institute Co. Ltd, Japan \\ ${ }^{2} J D R$ University, Japan
}

\begin{abstract}
Every day, a huge amount of waste lubricating oil (LO) is generated worldwide. It is feared that some of this waste oil is discarded or slips into the environment. We developed a novel technology that enables semi-permanent use of LO without generating any waste, compensating for lost oil and reducing LO consumption. This technology keeps LO clean much like our kidneys clean our blood; the technology is therefore called a kidney system. The kidney system has been working well in many marine and cogeneration diesel engines, hydraulic machines, and machine workshops. The authors have also applied the kidney system to various environmental problems by custom remodelling it for each specific application. Focusing on preventing pollution of coastal sea, this paper reports the authors' rationale for this research and the waste oil situation both in Japan and abroad and gives an outline of the technology we developed. Furthermore, a case in which the authors succeeded in preventing waste oil from polluting rivers and neighbouring coastal sea is presented. The waste oil was generated in air compressors of a fertilizer plant as a mixture of LO and cooling water; i.e. emulsion of oil in water $(\mathrm{O} / \mathrm{W})$.

Keywords: no waste oil, semi-permanent use of engine oil, emulsion of oil in water, waste oil from compressors, fertilizer plants, slip of oil, pollution of river and coastal sea.
\end{abstract}

\section{Introduction}

The authors have been engaged in developing a system of technologies for provision of clean fuel oil, clean lubricating oil (LO) [1], and clean water [2]. 
The clean LO technology can keep LO permanently clean in machines and has been working well in many engines and hydraulic machines [1]. Practical application of this clean LO technology has proved very useful for saving natural resources and protecting the environment by: 1) enabling semi-permanent use of LO without creating waste oil; 2) prolonging life of machines by reducing wear; and 3 ) preserving efficiency of machines.

This paper reports the authors' R\&D philosophy and the current situation of waste oil in Japan and abroad, and provides an outline of the clean LO technology we developed. In addition, a case in which the technology was used to prevent possible pollution of rivers and neighboring coastal sea by LOpolluted waste water from air compressors at a Japanese fertilizer plant is presented.

\section{Research stance}

In 1994, the authors began to share data and ideas that were considered quite ahead of the time because they focused on developing technologies for semipermanent use of natural resources and products rather than for recycling.

Their philosophy went as follows: by representing natural resources with water, this may be seen as borrowing water from our future grandchildren and hence we should return the borrowed water to our grandchildren (i.e. to nature) in clean condition. Thus this philosophy was called "Thought of Borrowing Water."

The authors believe that this philosophy and its related technologies should be known and used all over the world to ensure the future coexistence of humankind and nature. With this in mind, the authors are trying to verify the technology, write as many papers as possible, and construct a theoretical base of the technology, because any well-refined theory should not only incorporate all data within it but also predict what more can be done using the technology.

\section{Waste oil in Japan and the USA}

Tables 1 and 2 show total oil demand and waste in Japan and in the USA in 1991 $[3,4]$. Waste oil accounted for as much as $50 \%$ of the total demand in both countries. It seems that at least some of this waste oil was thrown out into the environment. Furthermore, the situation today remains about the same as that reported in 1991 in both countries as well as in some other countries [4].

Figure 1 shows waste oil flowing down a seaside cliff into sea. One newspaper reported that a number of drums of waste oil had been discarded into a hole dug for waste disposal. Some years later, namely in 1997, the waste oil was discovered exuding from the cliff [5]. According to another newspaper report, 55,000 drums of waste oil were left in a mountain area [6]. It is not known who left the waste oil there, and it was feared that the waste oil might permeate into soil and pollute underground water. Eventually, the local government disposed of the waste oil at a cost of JPY240 million (about $€ 1.7$ million). 
Table 1: $\quad$ Waste oil in Japan.

\begin{tabular}{|c|c|}
\hline LO demand & $2470 \mathrm{ML}$ \\
\hline Waste LO & $\begin{array}{c}1270 \mathrm{ML} \\
51.4 \%\end{array}$ \\
\hline
\end{tabular}

Table 2: $\quad$ Waste oil in U.S. (1991).

\begin{tabular}{|c|c|}
\hline LO demand & $9050 \mathrm{ML}$ \\
\hline Waste LO & $\begin{array}{c}5200 \mathrm{ML} \\
(53 \mathrm{~h})\end{array}$ \\
\hline
\end{tabular}

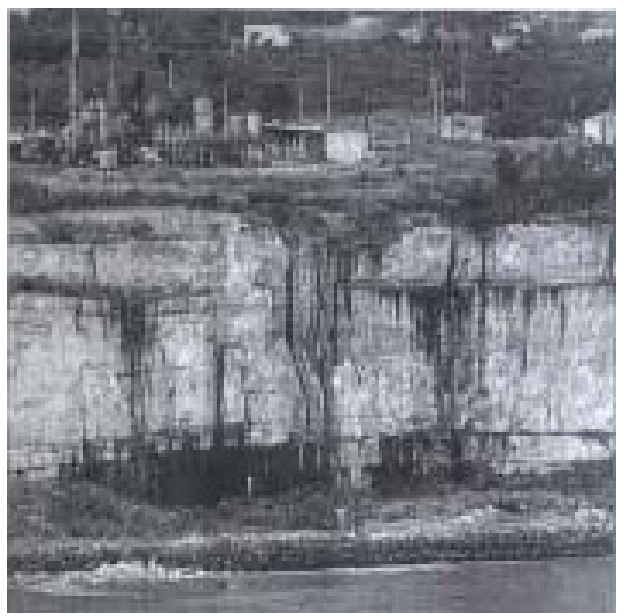

Figure 1: $\quad$ Waste oil flowing down a cliff into coastal sea.

\section{Outline of technology for preventing waste oil}

\subsection{Principle of new LO system}

Our new technology for preserving clean oil acts in the same way as our kidneys keep our blood clean and therefore it is referred to as an LO kidney system. The key element of this system is a newly developed filter. Human kidneys comprise 1 2 million filtration structures called nephrons [7], and so by analogy our newly developed filter is called a nephron filter.

Figure 2 shows comparison between conventional filters and the nephron filter. LO flows between sheets of filter paper in the nephron filter. Sludge particles sit on the filter paper and are removed while LO flows between the filter papers. Very small particles measuring $0.001 \sim 1 \mu \mathrm{m}$ in diameter are considered to obey Brownian motion [8]. Therefore the nephron filter is 
considered to remove particles as small as $0.001 \mu \mathrm{m}$ in diameter. Field data show that the nephron filter almost completely removes sludge particles larger than 1 $\mu \mathrm{m}$ as well as most fine particles measuring smaller than $1 \mu \mathrm{m}$, which conventional systems cannot remove.

Figure 3 shows the LO kidney system in marine and cogeneration diesel engines. Here, it comprises a nephron filter and small centrifugal separator of very simple structure. The conventional system removes sludge by large centrifugal purifiers with highly complicated structures and is not able to remove fine sludge particles. The amount of sludge therefore increases with running time using conventional LO systems and eventually LO must be changed with fresh oil in the conventional LO system.

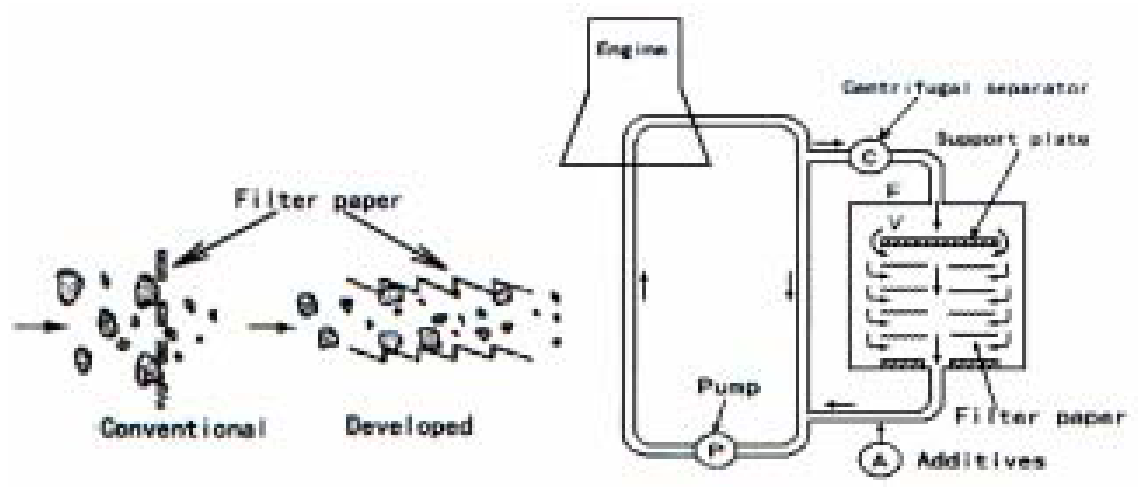

Figure 2: Comparison of filter. $\quad$ Figure 3: LO kidney system.

\subsection{Fundamental features of LO kidney system}

The kidney system has 2 features that conventional LO cleaning systems do not possess: 1) It can remove the majority of sludge particles smaller than $1 \mu \mathrm{m}$ as well as completely removing larger particles; and 2) it completely removes oxidized LO. All of the remarkable results of the kidney system derive from these 2 unique features.

Figure 4 shows that the kidney system almost completely removes oxidized LO [1] because no absorption of infrared (IR) radiation is observed near 1,710 waves/cm. When there is oxidized LO, strong IR absorption occurs at 1,710 waves/cm as shown by the broken line in fig. 4 .

Figure 5 shows the results of a comparison ship test of 3 cases: 1) no LO cleaning; 2) conventional LO system; and 3) kidney system [1]. In general, normal pentane (n-p) insoluble is used as index for contamination of LO. As shown in fig. 5, n-p insoluble was kept under 0.1 mass $\%$ for an extended period in the case of the kidney system, while it increased with running time in the other 2 cases. These results verify that the kidney system can keep LO clean for a long time due to the 2 fundamental properties mentioned above. 


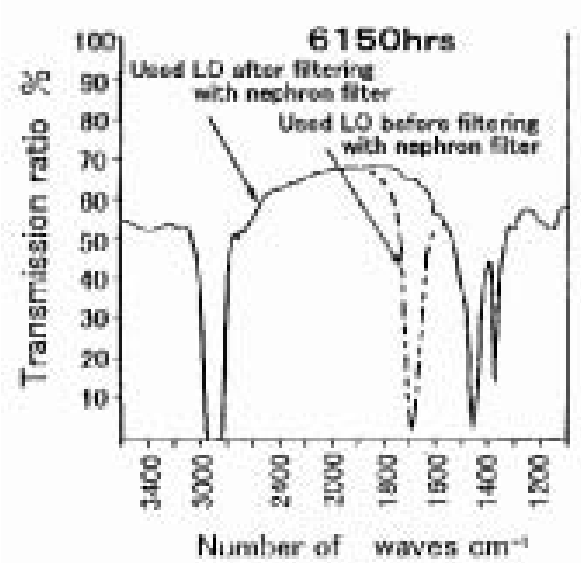

Figure 4: $\quad$ IR analysis of used oil. Figure 5:

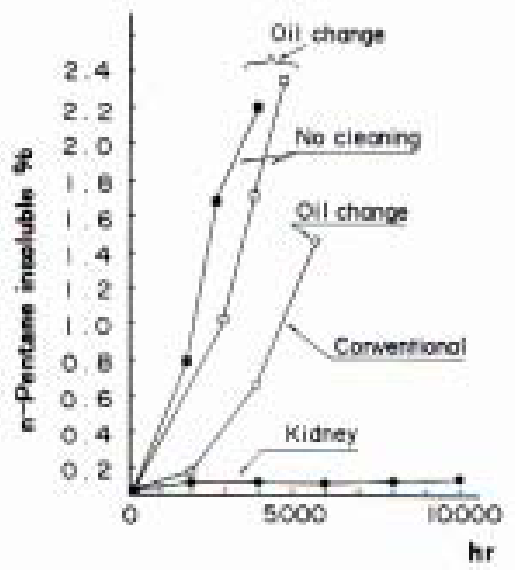

Field test comparing LO systems.

\section{Preventing pollution of river and coastal sea}

\subsection{Generation of waste oil at a fertilizer plant}

In fertilizer plants there is a process in which air is separated into oxygen and nitrogen. Air is therefore compressed by air compressors and cooled. Cooling after compression results in condensation of humidity and water generation. Some LO in the compressor mixes into this generated water and thereby produces emulsion of oil in water $(\mathrm{O} / \mathrm{W})$.

Water content of the emulsion reaches maximum value of about $99 \%$ during Japan's rainy season (June July) and minimum value of about $70 \%$ during the low-humidity winter season from December to February.

In the past, $\mathrm{O} / \mathrm{W}$ emulsion was generated and largely carried off-site by waste disposal companies. However, few restrictions were enforced regarding how and where these companies disposed the oil. It seems that a part of the $\mathrm{O} / \mathrm{W}$ emulsion was drained into rivers and coastal sea. For this reason, a system for recycling and semi-permanent use of compressor LO was planned so that no waste emulsion was required to be taken away from the plant.

\subsection{System for recycling waste oil}

The recycling system was designed based on the following principles:

1) Water in the $\mathrm{O} / \mathrm{W}$ emulsion should be evaporated by action of steam from steam boilers at the plant.

2) Residual LO should be cleaned by LO kidney system, namely by centrifugal separator and nephron filter. 
Figure 6 shows the schematic process of the recycling system, and fig. 7 shows the recycling unit. Each process is made in 1 unit in sequence. As shown, the system comprises 3 processes described as follows.

[Process 1]

During this process as much as $90 \%$ of water in the emulsion is evaporated. The process works as follows:

1) Waste emulsion is supplied into the tank as shown in fig. 6.;

2) Waste emulsion is heated by steam at around $100 \sim 110^{\circ} \mathrm{C}$;

3) Air is supplied into the tank so that waste $\mathrm{W} / \mathrm{O}$ emulsion may be well mixed and to allow uniform heating;

4) Water is evaporated until water content decreases below $10 \%$;

5) At the end of this process, waste water becomes waste oil including about $10 \%$ water.
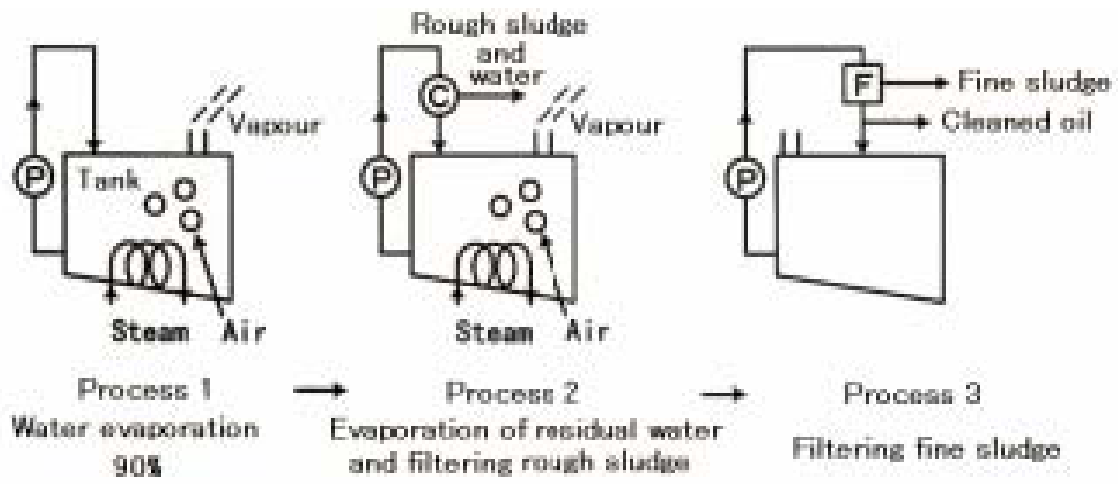

Figure 6: Schematic view of recycling process.

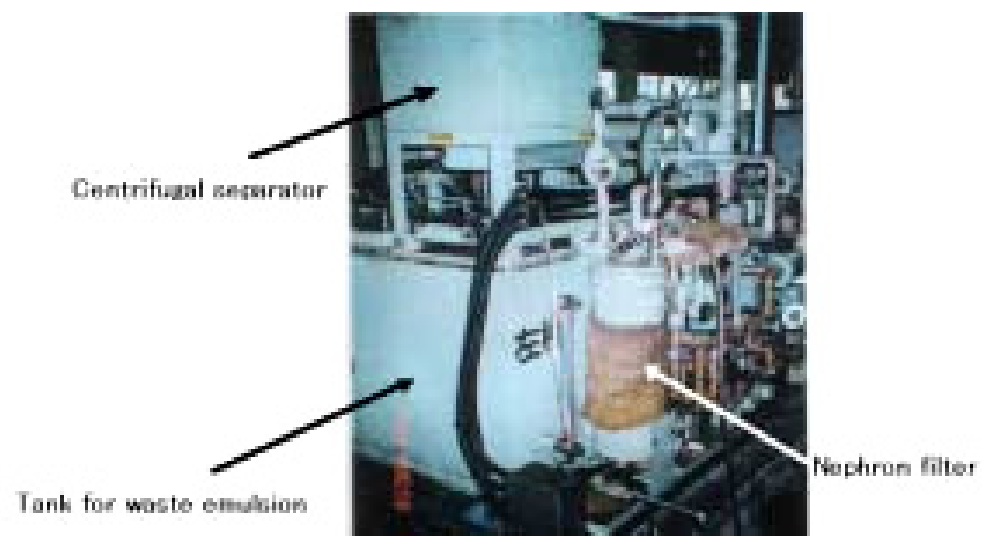

Figure 7: Recycling unit. 
[Process 2]

The purpose of this process is to evaporate almost all remaining water and to remove rough sludge by centrifugal separator. The process works as follows:

1) waste oil is heated to around $110 \sim 120^{\circ} \mathrm{C}$ and almost all remaining water is evaporated;

2) air is supplied as in process 1 ;

3 ) the centrifugal separator removes rough sludge together with water. [Process 3]

The purpose of this process is to remove fine sludge from waste LO by nephron filter to produce recycled LO.

\subsection{Recycling result}

Figure 8 shows a schematic view of the change from fresh LO to recycled LO.

Figure 9 shows: 1) fresh LO; 2) waste water (waste emulsion); 3) sample after process 1 ; 4) sample after process 2 ; and 5) recycled LO.

Figure 9 (1) shows fresh LO of NAS grade 9.

Figure 9 (2) is waste water of O/W emulsion with $99 \%$ water content from air compressors of the fertilizer plant. It has milky appearance with $1 \%$ oil content in water.

Figure 9 (3) shows heated and condensed waste water after process 1, in which steam heats waste water to around $100 \sim 110^{\circ} \mathrm{C}$. At this point, it is emulsion of water in oil with $10 \%$ water content. It is opaque and light brown in color.

Figure 9 (4) shows a sample after process 2 in which almost all water is evaporated and rough sludge removed by centrifugal separator. It is black due to the presence of many fine sludge particles.

Figure 9 (5) shows finally recycled LO after process 3 , in which fine sludge particles are removed by nephron filter. As shown, the recycled LO is transparent and cleaner than fresh LO: recycled LO is of NAS grade 8 in comparison with NAS grade 9 of fresh LO.

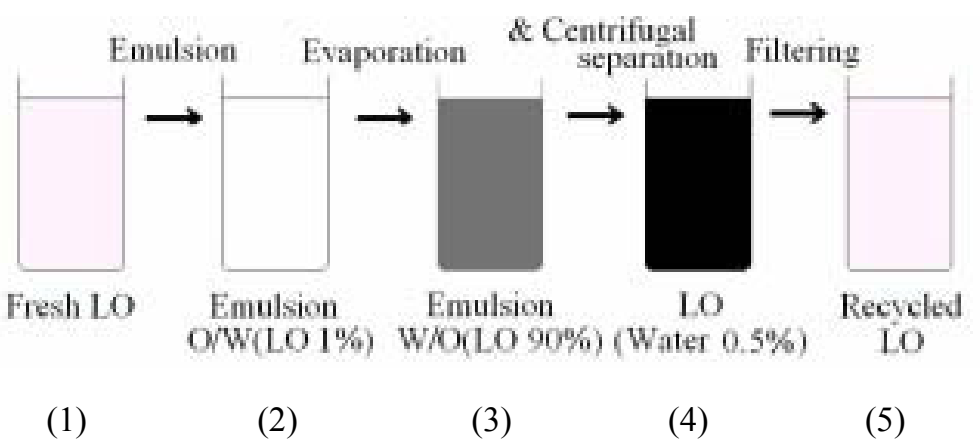

Figure 8: Schematic view of change. 


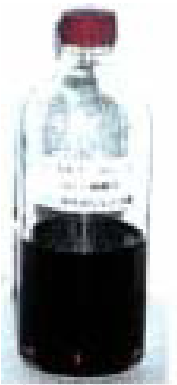

Fresh LO

NAS No. 9

Clean

(1)

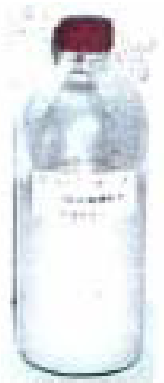

Emulsion O/W(LO 1\%)

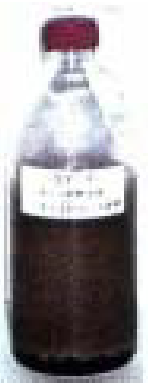

Emulsion

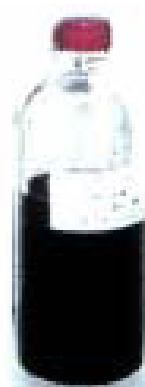

LO

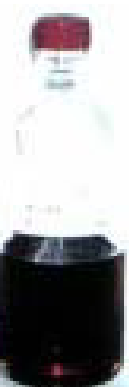

Recycled
Milky white

(2)
Light brown

(3)
Black

(4)

\section{Transparent}

(5)

Figure 9: Results of recycling process.

Table 3: $\quad$ Analysis of compressor oil.

\begin{tabular}{|c|c|c|c|}
\hline Itum & $\begin{array}{c}\text { Tresh } \\
\text { oal }\end{array}$ & $\begin{array}{c}\text { Waste oll } \\
\text { Mrter Pmease } 1\end{array}$ & $\begin{array}{c}\text { Fecrucled } \\
\text { oll }\end{array}$ \\
\hline Dureaity $\boldsymbol{V} / \mathrm{cm}$ & 0.881 & 0.825 & 0.894 \\
\hline Flush point $t$ & 285 & - & 275 \\
\hline $\begin{array}{c}\text { Kinamatie viscusity } \\
\text { eSt 40t }\end{array}$ & 149.2 & - & 1502 \\
\hline $\begin{array}{c}\text { Tetal acis numter } \\
\text { makon } / \mathrm{s}\end{array}$ & 0.17 & 0.60 & 0.18 \\
\hline $\begin{array}{l}\text { Base number } \\
\text { makOH/ge }\end{array}$ & 1.50 & 0.45 & 1,30 \\
\hline $\begin{array}{l}\text { Whater } \\
\mathbf{s}\end{array}$ & 0 & 12.5 & 0,02 \\
\hline $\begin{array}{l}\text { Studgr } \\
m \varepsilon / 100 \mathrm{~mL}\end{array}$ & o & 35 & 10 \\
\hline
\end{tabular}

\section{Discussion}

\subsection{LO recycling}

Table 3 compares: 1) fresh LO; 2) waste emulsion after process 1 , in which more than $90 \%$ water is evaporated; and 3) recycled LO. Waste LO differs from fresh LO in all measured items; it contains $12.5 \%$ water because process 1 evaporates $90 \%$ water. It includes as much as $35 \mathrm{mg} / 100 \mathrm{~mL}$ sludge that may have been generated in the air compressors.

On the other hand, recycled LO is almost the same as fresh LO, except for sludge $10 \mathrm{mg} / 100 \mathrm{~mL}$. According to the present standard, the nephron filter is renewed when recycled LO contains sludge $12 \mathrm{mg} / 100 \mathrm{~mL}$. Immediately after filter replacement, there is no sludge at all and recycled LO appears cleaner than fresh LO. 
The results of the field test verify that the recycling system shown in figs. 6 and 7 enables complete recycling of waste $\mathrm{O} / \mathrm{W}$ emulsion from air compressors at the fertilizer plant. The success of the system has led to the following results:

1) All water in waste $\mathrm{O} / \mathrm{W}$ emulsion is evaporated by the extra steam available in the plant.

2) No waste water polluted with oil is exhausted out of the plant, alleviating fears that polluted waste water could be thrown out into the environment, especially into nearby rivers and coastal sea.

3) Recycling of waste LO reduced LO consumption to about $1 / 10$.

\subsection{Closed plant system with no waste water and no waste oil}

The authors solved the problem of possible pollution of rivers and neighboring coastal sea with waste oil from compressors at a Japanese fertilizer plant. Since that time, laws for environment protection have been tightened and the situation is better than in former times.

The danger remains, however, that pollution of rivers and coastal sea may occur at any time by spillage or slick of oil. LO is widely used at many plants and workshops, and oil-containing waste water from these facilities could flow into rivers and coastal sea.

To solve such problems, systems that do not produce any waste oil and waste water are desirable. To this end, the authors constructed a plant that produces no waste oil and waste water in Thailand. This was realized by combining LO kidney system and water kidney system.

Water kidney system utilizes rain water and recycles waste water from the plant. An artificial river built around the plant biologically cleans the waste water. Biological cleaning means that various plants, aquatic fauna, and bacteria in the river clean the waste water without any chemical processing.

\subsection{Reduction of oil consumption expected by UK government}

The science of tribology was started according to a report by a committee sponsored by the UK Government in 1964 [9]. In this report, the committee expected that LO lifetime should be lengthened and LO consumption reduced by about $20 \%$. The authors have succeeded in lengthening LO life semipermanently and in reducing LO consumption to about $1 / 5 \sim 1 / 10$ in engines and other machines.

\section{Conclusion}

The authors have successfully developed a technology called a kidney system that enables semi-permanent use of lubricating oil without producing any waste oil. It also enables to reduce oil consumption to $1 / 5 \sim 1 / 10$ in comparison with the conventional system. By applying the kidney system to recycle waste $\mathrm{O} / \mathrm{W}$ emulsion from air compressors at a fertilizer plant in Japan, the following results were obtained: 
1) Waste LO was separated from waste emulsion and completely recycled.

2) Thus, the recycling system has been preventing possible pollution of the neighbouring rivers and coastal sea since 1996.

3) Recycling of LO has greatly reduced LO consumption to about $1 / 10$ at the fertilizer plant.

\section{References}

[1] Morio, S. \& Tadanori, A., Reduction of operation and maintenance cost by technology for clean engine, Pro. of the 7th International Symposium on Marine Engineering, Tokyo, October 24th to 28th, 2005, 33-3, Paper 56.

[2] Somchet Koomsorn et al, A No Waste Water Plant with Minimum City Water Supply Utilizing and Recycling Rain Water, 6th International Conference on The Environmental Management of Enclosed Coastal Seas (EMECS), 2003, November 18 21, 2003, Bangkok, Thailand, Abstract, pp141.

[3] Investigation Report on Recycling Petroleum, Japan Institute of Applied Energy (March 1992), pp62-63.

[4] Investigation Report on Recycling Lubricating Oil, Japan Lubricating Oil Society (March 1997), pp72-92.

[5] The Asahi Shinbun (Japanese newspaper), Wednesday, October 22, 1997 , Evening edition.

[6] The Yomiuri Shinbun (Japanese newspaper), Wednesday, November 11, 1998, Evening edition.

[7] Taizo, S., Kyoji, T. \& Toshiyuki, Y., Physiology for university students, Nonkoh-dou (September 1995), pp204.

[8] Douglas, H. Everett, Science of Colloid (in Japanese), Kagaku, Dojin (1992), pp5.

[9] Kazuo, K. The world of friction, Iwanami Sinsyo in Japan (1994), pp169. 